\title{
JOGOS DIGITAIS COMO RECURSO DE INCENTIVO À LEITURA: UMA REVISÃO SISTEMÁTICA
}

\author{
Luana Monique Delgado Lopes - PPGTIC/UFSC - luanamonique@gmail.com \\ Kajiana Nuernberg Sartor Vidotto - PPGTIC/UFSC - kajianansartor@ gmail.com \\ Eliane Pozzebon - PPGTIC/UFSC - eliane.pozzebon@ufsc.br \\ Luciana Bolan Frigo - PPGTIC/UFSC - luciana.frigo@ufsc.br
}

\begin{abstract}
RESUMO: A utilização de jogos digitais como recurso de incentivo à leitura ainda é uma prática incipiente e que carece de mais estudos para aprofundamento do tema. A fim de obter uma maior apropriação do assunto realizou-se uma revisão sistemática com o objetivo de verificar qual a relação existente entre os jogos digitais e a leitura nas publicações científicas no período compreendido entre o ano 2000 e o ano de 2017. Foi feita uma busca inicial nas bases de dados Scopus e Web of Science, seguida de uma avaliação em 2 etapas que resultou em uma análise crítica de 6 (seis) documentos. Constatou-se que as áreas abrangidas pelas publicações analisadas são: desenvolvimento de habilidades de leitura por meio de jogos digitais; letramento digital através de jogos; videogames enquanto cibertextos e uso de jogos educativos associados a práticas de leitura e escrita.
\end{abstract}

Palavras-chave: Jogos Digitais. Leitura. Letramento Digital. Revisão Sistemática.

\section{DIGITAL GAMES AS A RESOURCE TO ENCOURAGE THE HABIT OF READING: A SYSTEMATIC REVIEW}

\begin{abstract}
The use of digital games as a resource to encourage reading is still an incipient practice and needs further study to deepen the subject. In order to obtain a greater appropriation of the topic, a systematic review was carried out for the purpose of verify the relationship between digital games and reading in scientific publications between the year 2000 and 2017. An initial search in the Scopus and Web of Science databases was made, followed by a 2-step evaluation that resulted in a critical analysis of 6 (six) documents. It was found that the areas covered by the analyzed publications are: development of reading skills through digital games; digital literacy through games; video games as cybertexts and use of educational games associated with reading and writing practices.
\end{abstract}

Keywords: Digital Games. Reading. Literacy. Systematic Review.

\section{INTRODUÇÃO}

A interação com jogos digitais tem iniciado cada vez mais cedo nas novas gerações. Jogar através de computadores, tablets, consoles e smartphones é uma atividade presente desde a mais tenra infância e uma das principais fontes de lazer entre crianças e adolescentes. Por serem artefatos atrativos para o público jovem, muitos professores têm utilizado os jogos digitais em suas práticas, podendo aliar desta forma, o aprendizado ao entretenimento. As vantagens da utilização de jogos digitais como recurso de aprendizagem de habilidades e conteúdos têm sido comprovadas por diversos pesquisadores (KIRRIEMUIR; MCFARLANE, 2004; MATTAR, 2010; PRENSKY, 
2012; MATOS; LIMA, 2015; PAULA; VALENTE, 2015; SCHAEFFER; ANGOTTI, 2016) trazendo um caráter utilitário ao hábito de jogar que muitos estudantes possuem.

Para Veen e Vrakking (2009) as novas gerações começam a aprender assim que passam a jogar em computadores e desenvolvem o gosto pelos jogos digitais ainda muito jovens. O hábito de ler, entretanto, principalmente entre estudantes jovens no Brasil, vem sofrendo uma diminuição nos últimos tempos, de acordo com as últimas pesquisas realizadas pelo Instituto Pró-Livro no país (INSTITUTO PRÓ-LIVRO, 2008, 2011). Observando a discrepância entre estes dois hábitos, pensou-se na seguinte questão: "Seria possível utilizar jogos digitais como recurso de incentivo ao hábito de ler?". Procurando subsídios para responder este questionamento foi realizada a revisão sistemática da literatura apresentada neste artigo, a fim de encontrar estudos sobre possíveis soluções envolvendo o uso de jogos digitais como recursos de incentivo à leitura.

\section{REFERENCIAL TEÓRICO}

\subsection{Leitura e Tecnologia}

A propagação dos computadores e da internet e o advento de novas tecnologias da informação e comunicação que vêm ocorrendo muito rapidamente, geram transformações nos hábitos e fazeres sociais de forma constante. Assim, mudaram também as formas de registro, disseminação e aquisição do conhecimento humano. Com o uso das novas tecnologias, as práticas de leitura e de escrita sofreram transformações e por conseguinte mudaram também as formas de ler. O surgimento de bibliotecas digitais e virtuais e de novos suportes de leitura, tais como blogs, e-books, entre outros, possuem também influência nos hábitos de leitura. (CHARTIER, 2010).

Para Marcuschi (2003), os leitores se comportam de formas diferentes conforme o suporte de leitura a que se submetem. Porém, isto não significa que diferentes suportes transmitam conteúdos diversos para os mesmos textos e sim, significa que dependendo do suporte, muda a nossa relação de leitor com os conteúdos de cada leitura. Assim, as mídias digitais, incluindo os jogos digitais se constituem em novos suportes de leitura, tendo como característica fundamental o fato de serem integrativas e colaborativas, o que muda as formas de ler e as práticas de leitura. (GEE, 2004).

\subsection{Letramento e Letramento digital}

Entende-se por letramento as práticas sociais de leitura e escrita e as situações de prática das mesmas, assim como sua influência na sociedade. (SOARES, 2002).

Dentro do cenário das novas tecnologias da informação e comunicação alterando os hábitos dos indivíduos dentre eles o da leitura e da escrita, surge então o conceito de letramento digital. Para Soares (2002), o letramento digital é uma condição ou um estado das pessoas que se apropriam das novas tecnologias digitais para exercer práticas de leitura e escrita através de telas [do computador, do smartphone, etc.]. Esta condição é diferente da situação dos indivíduos que exercem práticas de leitura e escrita no papel. Para Aquino (2005), o letramento digital está relacionado ao "domínio de técnicas e habilidades para acessar, interagir, processar e desenvolver uma multiplicidade de competências na leitura das mais variadas mídias". Ou seja, um entendimento possível do letramento digital é que ele significa ser capaz de usar as tecnologias mais recentes, lançando mão das novas formas de ler e escrever de acordo com os novos suportes digitais da informação perante a sociedade. 


\subsection{Jogos digitais e Leitura}

O conceito de jogos digitais envolve uma ideia muito mais abrangente do que pensarmos em videogames. O termo videogames estava sempre relacionado ao jogar através de um console ou de máquinas de fliperama, entretanto ainda é um termo bastante utilizado por alguns autores, conforme percebido na realização desta pesquisa.

O termo mais empregado atualmente é "jogos digitais". Pensar em jogos digitais envolve pensarmos em jogos disponíveis não só para consoles, mas para computadores, notebooks, tablets, smartphones e "qualquer outro dispositivo ou tecnologia digital que venha a existir". (ARRUDA, 2013).

Interagir com jogos digitais/videogames para Gee (2012), compreende uma nova forma de letramento, enquadrada dentro do letramento digital e pode ser um recurso para que a sociedade atual possa ir além do letramento voltado para a informação impressa. O autor faz ainda um comparativo dos livros com os videogames/jogos digitais. Para o autor, os videogames são criados com base na resolução de problemas e ele compreende que os livros também podem ser utilizados desta forma na escola. Os jogos também podem levar o jogador a pensar mais como um designer, como um desenvolvedor, levando os jogadores a projetar jogos, uma vez que muitos deles permitem o acesso ao código-fonte para modificá-lo. Esta estratégia pode ser comparada com o uso dos livros quando os alunos são ensinados a "ler como escritores", a produzirem também seus próprios escritos com base nas leituras que fizeram. Reforça ainda que os jogos podem ser jogados socialmente, envolvendo competição e colaboração, sendo que os livros também podem ser usados desta forma, desde que haja interesse da escola e dos professores nestas dinâmicas. (GEE, 2012).

Outro fator que liga os jogos à leitura de textos é que no decorrer de sua interação com o jogo, os jogadores são expostos a vários textos digitais que servem para auxiliá-los a resolver problemas no jogo, explorar os mundos apresentados e ainda se comunicar e colaborar com outros jogadores. Estas interações textuais durante o jogo contribuem para a aquisição do letramento digital, uma vez que os jogadores estão fazendo uso da escrita e da leitura para interagirem no meio social relativo ao jogo (GEE, 2004). Outras pesquisas (MELO; BERTAGNOLLI; TONELLO, 2016; MENDONÇA, 2015) apontam que utilizar jogos digitais para trabalhar o letramento e incentivar a leitura, é uma estratégia que permite ao aluno desenvolver novas formas de expressão e comunicação, diferentemente do que desenvolveu com as mídias impressas. Neste sentido, as mídias digitais surgem para trazer novas formas de letramento, não substituindo os suportes tradicionais de informação, mas sendo inclusive um meio de promover a leitura inclusive nos meios impressos.

\section{METODOLOGIA}

O método escolhido para a realização deste trabalho foi uma revisão sistemática da literatura (RSL). Para Kitchenham (2004), uma RSL pode fornecer um panorama geral sobre a área que se pretende estudar. Segundo Sampaio e Mancini (2007), uma revisão sistemática deve apresentar um planejamento e uma descrição metódica e explícita de seus procedimentos, de forma com que possa ser recriada por qualquer outro pesquisador.

Para a realização da revisão sistemática da literatura aqui apresentada, optou-se por utilizar o protocolo explicitado por estes mesmos autores. (SAMPAIO; MANCINI, 2007). Em seu artigo, Sampaio e Mancini orientam que se contemple as seguintes etapas para a execução do processo: 
- Definição da pergunta de pesquisa especificando a área de interesse;

- Determinação das bases onde serão executadas as pesquisas, explicitando os termos a serem utilizados e as estratégias de busca;

- Estabelecimento de critérios para selecionar os documentos;

- Realização da busca e extração dos resultados iniciais;

- Aplicação dos critérios para justificar possíveis exclusões de documentos;

- Fazer uma análise crítica resumindo as informações dos documentos incluídos na revisão;

- Apresentar uma conclusão apontando e discutindo os resultados mais relevantes obtidos com a revisão.

Assim, visando relacionar a utilização de jogos digitais como recurso de incentivo à leitura, partimos das seguintes questões de pesquisa para nortear a realização da revisão sistemática: (1) existem aplicações de jogos digitais neste sentido? (2) quais as principais temáticas e abordagens apresentadas nas publicações científicas relacionando jogos digitais e leitura?

\subsection{Fontes de pesquisa e estratégia de busca}

Foram selecionadas como fontes de pesquisa as bases de dados Web of Science e Scopus por se tratarem de bases internacionais e multidisciplinares, compreendendo publicações científicas das mais diversas áreas do conhecimento. Considerando que a maioria das publicações científicas são publicadas em língua inglesa, os termos escolhidos para a busca em ambas as bases foram "digital games", "videogames", "read", "habit", "practice" e "routine". A estratégia de busca utilizada foi construída nos campos de pesquisa avançada das bases de dados, através da combinação de símbolos de truncagem e operadores booleanos da seguinte maneira: "digital gam*" OR "videogam*" AND "read*" AND "habit" OR "practice" OR "routine". O operador OR serve para recuperar resultados que tragam tanto o termo videogame ou o termo digital game, bem como para recuperar tanto o termo "habit", "practice" ou "routine". Para combinar os termos, fazendo sua intersecção, foi utilizado o operador AND. Complementando a estratégia, foi utilizado o símbolo de truncagem asterisco (*), a fim de recuperar palavras iniciadas com o radical das palavras escolhidas. $\mathrm{O}$ uso deste símbolo permite recuperar termos como "videogaming", "digital gaming", "digital game", "digital games", "reader" e "reading", por exemplo.

A busca foi construída em cada base utilizando como destino da busca os campos referentes ao título, resumo e palavras-chave. As bases de dados, a query de busca e os resultados estão expostos no Quadro 1.

Quadro 1 - Pesquisa nas bases de dados

\begin{tabular}{|c|c|c|}
\hline $\begin{array}{c}\text { Base de } \\
\text { Dados }\end{array}$ & Query & Resultados \\
\hline Scopus & $\begin{array}{l}\text { TITLE-ABS-KEY(("digital gam*" OR "video gam*" } \\
\text { OR "videogam*") AND ("read*") AND ("habit" OR } \\
\text { "routine" OR "practice")) }\end{array}$ & 35 \\
\hline $\begin{array}{l}\text { Web of } \\
\text { Science }\end{array}$ & 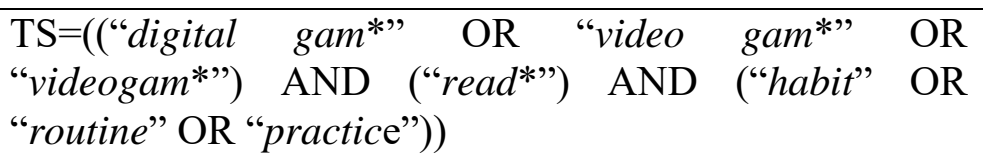 & 23 \\
\hline
\end{tabular}

Fonte: As autoras.

V. $15 \mathrm{~N}^{\circ}$ 2, dezembro, 2017 
Na base de dados Scopus, os termos foram pesquisados no campo que integra título do artigo, resumo e palavras-chave. Na Web of Science, a pesquisa foi realizada através do campo tópico. Este campo compreende também os itens título, resumo e palavras-chave. Além disso, compreendendo que os jogos evoluíram muito desde o início do século 21, para obter uma abordagem mais atual sobre a temática, foi realizada uma filtragem por ano de publicações compreendidas entre o período do ano 2000 a 2017. Esta busca inicial recuperou 35 documentos na base de dados Scopus e 23 na Web of Science.

\subsection{Dos critérios de inclusão e exclusão de documentos}

Após a busca inicial para selecionar os principais estudos e experiências de uso dos jogos digitais relacionados à leitura, foi feita uma seleção em 2 etapas.

Na primeira etapa, foram lidos os títulos e resumos de todos os documentos que estivessem em língua inglesa, portuguesa ou espanhola. Nesta pré-seleção foram incluídas as publicações que apresentavam nos campos de resumo e título alguma conexão entre os assuntos jogos digitais e leitura, ou jogos digitais e letramento, ou ainda jogos digitais e literatura. Estas conexões de assuntos foram escolhidas devido a sua relação com o hábito da leitura, com vistas a recuperar o maior número possível de estudos sobre o uso de jogos digitais no incentivo à leitura.

Além das obras que não apresentavam alguma conexão entre os assuntos de forma clara, foram excluídos também documentos duplicados nas duas bases e documentos cujo acesso não era gratuito ou não estava disponível o seu texto completo.

As 10 publicações obtidas na etapa da pré-seleção foram lidas em sua totalidade de forma a apreciar seus conteúdos a fim de obter uma seleção final de documentos para discutir e analisar.

Como critério de exclusão das publicações lidas integralmente, optou-se por excluir aquelas que não apresentavam nenhuma contribuição relacionando jogos digitais a leitura.

Quadro 2.

O número de documentos obtidos em cada fase da seleção está descrito no

Quadro 2 - Etapas da revisão

\begin{tabular}{|l|c|c|c|}
\hline \multirow{2}{*}{ Base de Dados } & \multicolumn{3}{|c|}{ Quantidade de documentos por etapa } \\
\cline { 2 - 4 } & Busca inicial & Pré-Seleção & Seleção Final \\
\hline Scopus & 35 & 8 & 4 \\
\hline Web of Science & 23 & 2 & 2 \\
\hline
\end{tabular}

Fonte: As autoras.

\subsection{Publicações selecionadas para análise crítica}

As publicações obtidas na seleção final foram separadas por área temática para melhor compreensão. Seu ano de publicação, autoria e título podem ser vistos no portfólio bibliográfico exposto no Quadro 3. Cabe salientar que todos os títulos foram traduzidos da língua inglesa para a língua portuguesa, com exceção do quinto artigo que já se encontrava nesse idioma. 
Quadro 3 - Portfólio bibliográfico

\begin{tabular}{|c|c|c|}
\hline Ano & Autoria & Título \\
\hline 2007 & Mikolaj Dymek & $\begin{array}{c}\text { Guerras de Exportação: Teoria da } \\
\text { Literatura e como ela explica a indústria do } \\
\text { videogame }\end{array}$ \\
\hline 2012 & $\begin{array}{l}\text { Thomas Apperley and } \\
\text { Christopher Walsh }\end{array}$ & $\begin{array}{l}\text { O que os jogos digitais e letramento têm } \\
\text { em comum: uma heurística para entender o } \\
\text { letramento dos alunos através dos games }\end{array}$ \\
\hline 2015 & Jeffrey Wood & $\begin{array}{l}\text { Múltiplas possibilidades: as vidas multi- } \\
\text { alfabetizadas de três crianças }\end{array}$ \\
\hline 2016 & $\begin{array}{c}\text { Angel Torres-Toukoumidis; } \\
\text { Luis Romero-Rodríguez; M. } \\
\text { Amor Pérez-Rodríguez; Staffan } \\
\text { Björk }\end{array}$ & $\begin{array}{l}\text { Desenvolvimento de habilidades de leitura } \\
\text { através de videogames: estado da arte }\end{array}$ \\
\hline 2016 & $\begin{array}{c}\text { Alexandre Caitano, Edjane de } \\
\text { Azevêdo, Marlla Viana } \\
\text { Departamento }\end{array}$ & $\begin{array}{c}\text { Letramento digital no ensino de língua } \\
\text { portuguesa em uma escola do semiárido } \\
\text { potiguar: os jogos educativos na mediação } \\
\text { do ensino-aprendizagem }\end{array}$ \\
\hline 2017 & $\begin{array}{l}\text { Michelle M. Neumann; Glenn } \\
\text { Finger; David L. Neumann }\end{array}$ & $\begin{array}{c}\text { Um framework conceitual para letramento } \\
\text { digital emergente }\end{array}$ \\
\hline
\end{tabular}

Fonte: As autoras.

\section{4 Áreas de enfoque das publicações}

As publicações analisadas foram separadas por área temática que abordaram quanto aos jogos digitais e leitura e estão apresentadas a seguir.

\subsubsection{Desenvolvimento de habilidades de leitura por meio de jogos digitais}

Torres-Toukoumidis et al. (2016) apresentam o estado da arte sobre o desenvolvimento de habilidades de leitura através de jogos digitais. As publicações científicas analisadas na revisão elaborada pelas autoras ficou centrada em três abordagens: propósitos de leitura através de videogames, estratégias de leitura através de videogames e habilidades de leitura através de videogames, mencionando também o letramento digital através de jogos.

\subsubsection{Letramento digital através de jogos}

Apperley e Walsh (2012) apontam que os jogos digitais e o letramento têm muito em comum. Os autores defendem que a leitura e escrita do que chamam de "paratextos" (textos relacionados aos jogos digitais - como de tutoriais, por exemplo) podem ser uma boa estratégia inicial para incluir os jogos digitais na aquisição do letramento e apresentam um método para auxiliar os professores na compreensão do letramento através de jogos digitais. Neste estudo, mostram que é importante que os professores compreendam de que maneira as ações, o design, as situações de jogo e os 
jogos enquanto sistema que engaja os alunos, podem afetar o ato de jogar e contribuir para a aquisição do letramento através do jogo.

Jeffrey Wood (2015) discorre sobre múltiplas formas de desenvolvimento do letramento em três crianças. Assim como em Apperley e Walsh (2012), a experiência relatada no artigo de Wood envolve o uso de textos sobre jogos como estratégia inicial para o desenvolvimento do gosto pela leitura. Após sentir a necessidade de ler tutoriais sobre o jogo Super Mario Bros., a criança analisada no artigo, acabou por si própria desenvolvendo o hábito da leitura.

Neumann, Finger e Neumann (2017) apresentam uma estrutura de desenvolvimento de habilidades de letramento digital emergente em complemento às habilidades de letramento tradicional. Para os autores, as interações socioculturais com textos digitais e não-digitais são capazes de promover o letramento e o letramento digital, sendo os jogos digitais importantes ferramentas dentro deste contexto. Através das experiências de interação com textos digitais e não-digitais, as crianças aprendem a se comunicar e construir conhecimentos.

\subsubsection{Videogames enquanto cibertextos}

Apesar de apresentar um viés basicamente todo voltado para a indústria de games, o artigo de Dymek (2007), traz um conceito interessante relacionado à leitura. $\mathrm{O}$ autor apresenta a teoria de Aarseth, que vê os videogames enquanto cibertextos, que requerem que os jogadores/leitores transformem seu papel de interpretadores textuais a intervencionistas textuais, já que enquanto jogam, podem ter controle da narrativa do jogo. Assim, o autor vislumbra um possível novo mercado para os videogames: o de produto cultural nesta perspectiva de cibertexto, o que tem direta influência sobre a leitura e as mudanças no hábito e nas formas de ler.

\subsubsection{Uso de jogos educativos associados à práticas de leitura e escrita}

Caitano, Azevêdo e Viana (2016) apresentam uma aplicação de jogos digitais no letramento digital de uma turma de $8^{\circ}$ ano do ensino fundamental em uma escola no Rio Grande do Norte, no Brasil. Através de oficinas foram aplicados jogos educativos como Soletrando e Jogo da Acentuação voltados ao ensino e aprendizagem de gramática visando aprimorar as habilidades de leitura e escrita dos alunos envolvidos. Entretanto, o artigo não apresenta uma avaliação da aprendizagem, focando apenas na narrativa das oficinas realizadas que tiveram como principal estratégia o uso dos jogos educativos como recurso de incentivo às práticas e melhoria das aptidões de escrita e leitura.

\section{ANÁLISE E DISCUSSÃO DOS RESULTADOS}

A análise das publicações baseou-se em atender o proposto pelo artigo, buscando responder os questionamentos de base da pesquisa apresentados na introdução. Assim, respondendo à questão número 1, pode-se dizer que sim, existem aplicações de jogos digitais como recurso de incentivo à leitura. Estas ações compreendem desde a formação do leitor até a promoção do hábito de ler diante de suas mudanças no contexto da nova sociedade da informação, enfocando principalmente na questão do letramento digital baseado em jogos digitais. Quanto ao segundo questionamento, pode-se dizer que a principal temática que relaciona jogos digitais e leitura encontrada nos artigos foi a abordagem de jogos digitais como nova forma de 
letramento digital, já que mesmo as publicações que não tiveram o letramento digital como tema central também se referiram ao assunto em algum momento.

\section{CONSIDERAÇÕES FINAIS}

Ao concluir esta revisão sistemática foi possível perceber que publicações relacionadas ao uso de jogos digitais como recurso de incentivo à leitura ainda são incipientes, principalmente no Brasil.

Considerando que dos seis artigos analisados, três abordam a questão do letramento digital baseado em jogos digitais podemos considerar que esta temática tem sido tendência nos trabalhos científicos envolvendo leitura e jogos digitais.

As estratégias de inclusão e exclusão de publicações permitiram a recuperação de um número bastante restrito de artigos, o que impossibilitou uma análise maior sobre o tema. Desta forma, sugere-se como trabalho futuro a realização de novas revisões sistemáticas, abrangendo outras bases de dados, bem como atribuindo novos descritores e estratégias de busca, pois acreditamos que a utilização de jogos digitais como recurso de incentivo à leitura é uma temática promissora, entretanto pouco estudada e difundida no meio acadêmico. Sugerimos também, a proposição de estratégias pedagógicas e modelos de como usar os jogos digitais no incentivo ao hábito de ler, visando contribuir com professores interessados em inovar suas práticas através do uso das tecnologias da informação e comunicação.

\section{REFERÊNCIAS BIBLIOGRÁFICAS}

APPERLEY, T.; WALSH, C. What digital games and literacy have in common: a heuristic for understanding pupils' gaming literacy. Literacy, v. 46, n. 3, p. 115-122, nov. 2012.

AQUINO, R. Usabilidade é chave para aprendizado em EAD. Disponível em: $<$ http://noticias.universia.com.br/destaque/noticia/2005/01/28/490613/usabilidade-echave-aprendizado-em-ead.html>. Acesso em: 1 maio. 2017.

ARRUDA, E. P. Fundamentos para o desenvolvimento de jogos digitais. Porto Alegre: Bookman, 2013. 112p. (Série Tekne).

CAITANO, A.; DE AZEVÊDO, E.; VIANA, M. Letramento digital no ensino de língua portuguesa em uma escola do semiárido potiguar: Os jogos educativos na mediação do ensino-aprendizagem. CEUR Workshop Proceedings. Anais...2016. Disponível em: <https://www.scopus.com/inward/record.uri?eid=2-s2.084989267363\&partnerID=40\&md5=2bbe9f7fafba96b4f23709cd9d7e50db>. Acesso em: 21 jul. 2017.

CHARTIER, R. Escutar os mortos com os olhos. Estudos avançados, v. 24, n. 69, p. 6-30, 2010.

DYMEK, M. Exporting wars: Literature theory and how it explains the video game industry. 3rd Digital Games Research Association International Conference: "Situated Play", DiGRA 2007. Anais...2007. Disponível em:

<https://www.scopus.com/inward/record.uri?eid=2-s2.0-

84873375019\&partnerID=40\&md5=44ed130d2d866f737172531d7a135bd2>. Acesso 
em: 23 jul. 2017.

GEE, J. P. What videogames have to teach us about learning and literacy. New York: Palgrave Macmillan, 2004.

GEE, J. P. The Old and the New in the New Digital Literacies. The Educational Forum, v. 76, n. 4, p. 418-420, 2012.

INSTITUTO PRÓ-LIVRO. Retratos da leitura no Brasil. Disponível em: $<$ http://www.snel.org.br/wpcontent/uploads/2012/08/pesquisa_habito_de_leitura_2008.pdf>. Acesso em: 04 maio. 2017.

INSTITUTO PRÓ-LIVRO. Retratos da Leitura no Brasil. p. 348, 2011. Disponível em: <

http://prolivro.org.br/home/images/relatorios_boletins/3_ed_pesquisa_retratos_leitura_I PL.pdf >. Acesso em: 05 jun. 2017.

KIRRIEMUIR, J.; MCFARLANE, A. Literature Review in Games and learning. Futurelab series, n. 8, 2004.

KITCHENHAM, B. Procedures for performing systematic reviews. Keele, UK, Keele University, v. 33, n. TR/SE-0401, p. 28, 2004.

MARCUSCHI, L. A. Gêneros textuais: definição e funcionalidade. In: Gêneros Textuais e Ensino. Rio de Janeiro, RJ: Lucerna, 2003.

MATOS, E. C. A.; LIMA, M. A. S. Jogos eletrônicos e educação: notas sobre a aprendizagem em ambientes interativos. RENOTE: Revista Novas Tecnologias na Educação, Porto Alegre, v. 13, n. 1, 2015.

MATTAR, J. Games em educação: como os nativos digitais aprendem. São Paulo, SP: Pearson, 2010.

MELO, C. V. DE; BERTAGNOLLI, S. DE C.; TONELLO, G. H. Do livro ao RPG: conexões entre arte literária e jogos digitais em educação. \#tear: Revista de Educação, Ciência e Tecnologia, v. 5, n. 2, p. 1-19, 2016.

MENDONÇA, A. N. F. DE. O jogo digital como incentivador da leitura em alunos do ensino médio. Porto Alegre: Universidade Federal do Rio Grande do Sul, 2015.

NEUMANN, M. M.; FINGER, G.; NEUMANN, D. L. A Conceptual Framework for Emergent Digital Literacy. Early Childhood Education Journal, v. 45, n. 4, p. 471479, 2017.

PAULA, B. H. de; VALENTE, J. A. Errando para aprender: a importância dos desafios e dos fracassos para os jogos digitais na educação. RENOTE: Revista Novas

Tecnologias na Educação, Porto Alegre, v. 13, n. 2, 2015

PRENSKY, M. Aprendizagem baseada em jogos digitais. São Paulo, SP: SENAC 
São Paulo, 2012.

SAMPAIO, R.; MANCINI, M. Estudos de revisão sistemática: um guia para síntese criteriosa da evidência científica. Revista Brasileira de Fisioterapia, v. 11, n. 1, p. 8389, 2007.

SCHAEFFER, A. G.; ANGOTTI, J. A. P. Jogos digitais na apropriação do conhecimento científico. RENOTE: Revista Novas Tecnologias na Educação, Porto Alegre, v. 14, n. 1, 2016.

SOARES, M. Novas Práticas De Leitura E Escrita: Letramento Na Cibercultura. Educação e Sociedade. v. 23, n. 81, p. 143-160, 2002.

TORRES-TOUKOUMIDIS, Angel et al. Development of reading skills through video games: State of the art. OCNOS, v. 15, n. 2, 2016.

VEEN, W.; VRAKKING, B. Homo zappiens: educando na era digital. Porto Alegre: Artmed, 2009.

WOOD, J. Multiple Possibilities: The Multi-literate Lives of Three Children.

Complicity-na international journal of complexity and education, v. 12, n. 1, p. 6785, 2015. 